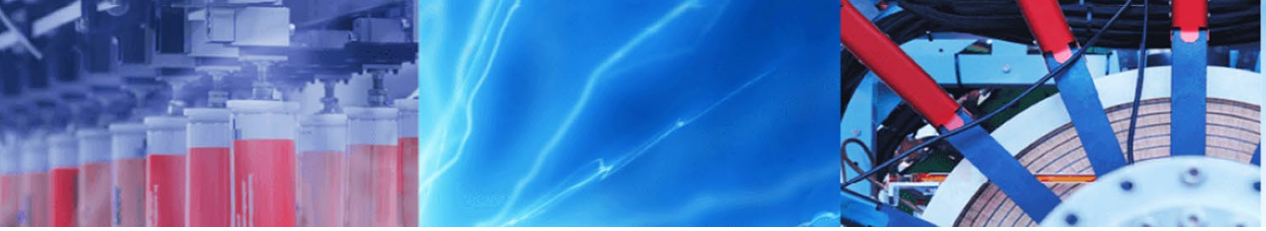

Research Article

\title{
Effects of oxygen content of pitch precursors on the porous texture and surface chemistry of pitch-based activated carbon fibers
}

\author{
Hanpeng Wang ${ }^{1} \cdot$ Jianxiao Yang ${ }^{1,2}$ (D) Jun $\mathrm{Li}^{3} \cdot \mathrm{Kui}^{\mathrm{Shi}}{ }^{1} \cdot \mathrm{Xuanke}_{\mathrm{Li}} \mathrm{i}^{1,2}$
}

(c) Springer Nature Switzerland AG 2019

\begin{abstract}
Oxidized pitches with different oxygen content were prepared using ethylene tar as a raw material by air-blowing method, then the resultant pitch-based activated carbon fibers (ACFs) were prepared through spinning, stabilization, carbonization, and $\mathrm{CO}_{2}$ activation processes. The results showed that the oxygen content of prepared oxidized pitch was up to $4.44 \%$ when the basic pitch was air-blown at $250{ }^{\circ} \mathrm{C}$, and the BET surface area of the corresponding ACF was up to $1047 \mathrm{~m}^{2} / \mathrm{g}$ with $0.536 \mathrm{mmol} / \mathrm{g}$ carboxylic group, $0.043 \mathrm{mmol} / \mathrm{g}$ lactonic group and $0.193 \mathrm{mmol} / \mathrm{g}$ phenolic hydroxyl group on the surface after $900^{\circ} \mathrm{CCO}_{2}$ activation. It revealed that the spinnability of oxidized pitch became poor as increasing its oxygen content, while the obtained carbon fiber was easy to be activated and the prepared ACF was equipped with large specific surface area and rich surface functional groups. However, the pore structure was easy to collapse and the surface area was seriously decreased when the oxygen content of pitch precursor was too high. Therefore, the property regulation of pitch precursor could effectively improve the porous texture and surface chemistry of the resultant ACF.
\end{abstract}

Keywords Ethylene tar $\cdot$ Pitch $\cdot$ Air-blowing $\cdot \mathrm{CO}_{2}$ activation $\cdot$ Activated carbon fiber

\section{Introduction}

Porous carbon materials have great advantages in environmental governance due to their characteristics of hydrophobicity, high chemical stability and thermal stability, large surface area and abundant pore structure [1-3]. Among them, activated carbon fiber (ACF) is attracting more and more attention as a novel porous carbonaceous material with excellent properties. Compared with commercial activated carbon (AC), ACF has the advantages of larger adsorption capacity, faster intramolecular adsorption kinetics and flexible engineering application [4-6], which make it widely used in the fields of hydrogen storage [7], air purification [8] and waste water treatment [9], and so on. However, higher production cost than AC limits the application of ACF. Therefore, it is particularly important to further improve the adsorption capacity of ACF on the premise of reducing cost. The pore structure and surface chemical composition of ACF have great influence on its adsorption capacities, so it is of great significance to explore the regulation mechanism of ACF pore structure and surface chemical composition to improve its adsorption capacity. At present, the regulation of ACF pore structure and surface chemistry is mainly focused on the improvement of activation methods and conditions. They compared chemical activation with physical activation [10], and proposed new activation methods such as direct activation [11], catalytic activation [12] and microwave activation [13], but these methods could only prepare ACF with specific structure, while the regulation mechanism of ACF pore structure and surface chemistry could not be systematically understood without studying

$\triangle$ Jianxiao Yang, yangjianxiao@hnu.edu.cn | ${ }^{1}$ College of Materials Science and Engineering, Hunan University, Yuelu, Changsha 410082, Hunan, China. ${ }^{2}$ Hunan Province Key Laboratory for Advanced Carbon Materials and Applied Technology, Hunan University,

Yuelu, Changsha 410082, Hunan, China. ${ }^{3}$ School of Chemistry and Biological Engineering, Changsha University of Science and Technology, Changsha 410114, China.

SN Applied Sciences (2019) 1:248 | https://doi.org/10.1007/s42452-019-0282-1 
the carbonaceous precursor. However, the properties of carbonaceous precursor have a significant effects on the development of pore structure and surface chemistry of ACF [14], and to some extent determine the properties of resultant ACF. Hence, recently the research of carbonaceous precursor catches extensive attention. Derbyshire et al. [15] prepared isotropic pitches from four different raw materials (coal-tar pitch, coal extracts solutions, shale oil and petroleum) to serve as the precursors to compare the formation and properties of ACF from different precursors. Vilaplana-Ortego et al. [16] used coal tar pitch and petroleum pitch as the precursors to explore the influence of different precursors on the pore structure of resultant ACF. Tekinalp et al. [17] studied the effects of molecular composition and structure of a given isotropic pitch precursor on the pore size distribution and adsorption behavior of ACF. Moreover, oxygen presented in the precursors also has a significant impact on the properties of ACF. Proper oxidation treatment can make the aromatic molecules in pitch precursor polymerized into non-planar macromolecules, and the aromatic compounds in pitch can be selectively oxidized into oxygen functional groups such as benzene polycarboxylic acids $[18,19]$. The subsequent carbonization and activation process may be impacted to improve the pore structure and surface chemical properties of the resultant $A C F$, thus promising to prepare ACF with better adsorption performance.

Therefore, in this work we attempted to regulate the pore structure and surface chemistry of ACF by changing the oxygen content of pitch precursors. Ethylene tar (ET) was used as a raw material to prepare the pitch precursors considering that ET is a byproduct from naphtha cracking process with low cost and a large scale production, which is a complex compound consisting of almost 1-2 cyclic compounds [20]. Air-blowing is the most widely used method to regulate the properties of pitch due to its low cost and simple operation [21,22], so we adjusted the oxygen content of the pitch precursors by the air-blowing method under different oxidation temperatures. As to activation method, physical activation with $\mathrm{CO}_{2}$ or $\mathrm{H}_{2} \mathrm{O}$ is the usual procedure to obtain ACFs. Although the cost of $\mathrm{H}_{2} \mathrm{O}$ activation is low, the gas flow of $\mathrm{H}_{2} \mathrm{O}$ steam is difficult to control. With $\mathrm{CO}_{2}$ activation, the temperature of the activation reaction is easier to control, so $\mathrm{CO}_{2}$ activation is more conducive to investigate the regulation of the properties of prepared ACFs. Therefore, the pore structure and surface chemistry of resultant ACFs prepared from pitch precursors with different oxygen contents under $\mathrm{CO}_{2}$ activation were compared.

\section{Experimental}

\subsection{Materials}

The ET (Wuhan Luhua Yueda Chemical Co. LTD, China) was used as a raw material for preparing spinnable pitch, which is completely soluble in toluene.

\subsection{Preparation of oxidized pitch precursors}

The oxidized pitch precursors were prepared by the airblowing method as follows: Firstly, the ET was distilled at $250^{\circ} \mathrm{C}$ for $3 \mathrm{~h}$ in the $3 \mathrm{~L} / \mathrm{min} \mathrm{N}_{2}$ mood to remove the light components to obtain basic pitch. Then, the basic pitch was air-blown at different oxidation temperature $(200,250$, $300{ }^{\circ} \mathrm{C}$ ) for $3 \mathrm{~h}$ in the $3 \mathrm{~L} / \mathrm{min}$ air mood to attain oxidized pitches. Finally, the oxidized pitches were further heat treated at $320^{\circ} \mathrm{C}$ for $3 \mathrm{~h}$ in the $3 \mathrm{~L} / \mathrm{min} \mathrm{N}_{2}$ mood in order to obtain the spinnable pitches with high softening point (SP) of approximately $200^{\circ} \mathrm{C}$. The resultant ET-derived oxidized pitch precursors were labeled as ETP-200, ETP-250, ETP-300, respectively. For comparison, the ET was directly distilled at $320^{\circ} \mathrm{C}$ for $5 \mathrm{~h}$ in the $3 \mathrm{~L} / \mathrm{min} \mathrm{N}_{2}$ mood to prepare the ET-derived spinnable pitch (ETP).

\subsection{Preparation of pitch-based activated carbon fibers}

The prepared ETP, ETP-200, ETP-250, ETP-300 were spun into pitch fibers using a melt spinning method with a single-hole spinneret (diameter $=0.2 \mathrm{~mm}$, length $/$ diameter $=3$ ) at the spinning temperature of their $\mathrm{SP}+50^{\circ} \mathrm{C}$. Then the obtained pitch fibers were stabilized from room temperature to $250^{\circ} \mathrm{C}$ for $1 \mathrm{~h}$ with an air flow of $200 \mathrm{~mL} /$ $\mathrm{min}$, the stabilized fibers were successively carbonized at $800^{\circ} \mathrm{C}$ for $1 \mathrm{~h}$ with a nitrogen flow rate of $100 \mathrm{~mL} / \mathrm{min}$ in corundum tube furnace. Lastly, the carbonized fibers (CFs) were activated under a $\mathrm{CO}_{2}$ flow of $0.5 \mathrm{~L} / \mathrm{min}$ at $900^{\circ} \mathrm{C}$ for $1 \mathrm{~h}$ with a heating rate of $5^{\circ} \mathrm{C} / \mathrm{min}$. The obtained ETderived pitch based ACFs were marked as ETP-ACF, ETP200-ACF, ETP-250-ACF, ETP-300-ACF, respectively.

\subsection{Characterization of pitches and fibers}

The SP and rheological properties of pitch precursors was determined by a capillary rheometer (CFT-100EX, Shimadzu). The chemical compositions and structures of pitch precursors were determined using an elemental analyzer (Vario ELIII, Elementar), a fourier transform infrared spectrometer (FITR, Nicolet iS10, Thermo Fisher Scientific), and X-ray diffraction (XRD, D2500X, Rigaku) with $\mathrm{CuKa}_{2}$ 
radiation, respectively. Besides the oxygen content was calculate by the subtracting method $(\mathrm{O}=100-\mathrm{C}-\mathrm{H}-\mathrm{N}-\mathrm{S})$. The thermogravimetric (TG) properties of pitch precursors were measured using a thermal analyzer (STA 449, Netzsch). The morphology of the prepared CFs and ACFs were observed by scanning electron microscopy (SEM, JSM-6700F, Joel) under the acceleration voltage of $20 \mathrm{kV}$. The porous textures of the obtained ACFs were characterized by $\mathrm{N}_{2}$ adsorption isotherms at $77 \mathrm{~K}$ with a specific surface area analyzer (TriStar II 3020, Micromeritics). Brunauer-Emmett-Teller (BET) equation was used to calculate the BET specific surface area $\left(\mathrm{S}_{\mathrm{BET}}\right)$, and the $t$-plot method was applied to evaluate the micropore volumes $\left(\mathrm{V}_{\text {mic }}\right)$, and the total pore volume $\left(\mathrm{V}_{\mathrm{t}}\right)$ was evaluated at a relative pressure of 0.99 . The pore size distribution of ACFs was analyzed by density functional theory. Meanwhile, the concentrations of oxygen functional groups for each ACF were measured by Boehm titration [23]. During the Boehm titration analysis, weighed amounts of ACFs $(0.2 \pm 0.0001 \mathrm{~g})$ were mixed with a volume of $50 \mathrm{~mL} 0.1 \mathrm{M}$ $\mathrm{NaHCO}_{3}, 0.05 \mathrm{M} \mathrm{Na}_{2} \mathrm{CO}_{3}$, and $0.1 \mathrm{M} \mathrm{NaOH}$ in a $150 \mathrm{~mL}$ flask. The base solutions without adding ACFs were used as blank runs. The flasks were sealed and then shaken for $24 \mathrm{~h}$ with $150 \mathrm{rpm}$ at $25^{\circ} \mathrm{C}$. Afterward, the suspensions were filtrated with qualitative filter paper. $10 \mathrm{~mL}$ of filtrate for each flask was mixed with $20 \mathrm{~mL} 0.1 \mathrm{M} \mathrm{HCl}$, and $0.1 \mathrm{M}$ $\mathrm{NaOH}$ was used to back titrate the solution while stirring. The number of acidic functional groups was determined and calculated under the assumption that $\mathrm{NaHCO}_{3}$ neutralizes carboxylic groups; $\mathrm{Na}_{2} \mathrm{CO}_{3}$ neutralizes both carboxylic groups and lactonic group; and $\mathrm{NaOH}$ neutralizes phenolic hydroxyl groups, as well as lactonic groups and carboxylic groups.

\section{Results and discussion}

\subsection{General properties and structural characterization of pitch precursors}

The SP, yield and elemental analysis results of the four pitch precursors are listed in Table 1. The SP of four pitches was around $200^{\circ} \mathrm{C}$ after distilled treatment. Compared to ETP, oxidized pitch had higher yield and the yield increased gradually as increasing the temperature of air-blowing. It suggested that air-blowing could increase the yield of pitch due to the introduced oxygen. The oxygen content of oxidized pitch had an evident uptake comparing to that of ETP as shown in Table 1. Moreover, the oxygen content increased continuously with the increase of air-blowing temperature, as ETP-200 was 4.45\%, ETP-250 was $5.34 \%$ and ETP-300 was up to $6.01 \%$, respectively. These showed that the air-blowing method can effectively increase the oxygen content of pitch precursors, and the oxygen content of pitch precursors could be controlled by altering the air-blowing temperature. The main mechanism during the air-blowing process could be the oxidation of both $\mathrm{Ar}-\mathrm{Ar}$ structure (biphenyl structure) generated by the decomposition of naphthenic structures and the alkyl side chains which leads to the formation of oxygen groups [24]. Therefore, it can be inferred that some oxygen functional groups (hydroxyl, carbonyl, carboxyl) could form during the controlled oxidative treatment.

The viscosity-temperature curves of the four pitch precursors are shown in Fig. 1a. All pitch precursors showed great rheological properties, which was in favor of the spinnability of pitch. Figure $1 \mathrm{~b}$ shows the TG curves of the four pitch precursors. Oxidized pitch generally had more weight loss than that of ETP, which illustrated that the introduced oxygen in oxidized pitch promoted the oxidative decomposition of pitch during heat treatment.

The FT-IR spectra of four pitch precursors are shown in Fig. $1 \mathrm{c}$. The wide and sharp absorption peak in $3300 \mathrm{~cm}^{-1}$ to $3600 \mathrm{~cm}^{-1}$ was attributed to $\mathrm{O}-\mathrm{H}$ stretching vibration, and the strong absorption peak at $2920 \mathrm{~cm}^{-1}$ was assigned to the $-\mathrm{CH}_{2}$ - stretching vibration, respectively [25]. The sharp peaks at $1600 \mathrm{~cm}^{-1}$ indicated the existence of $C=C$ skeletal vibration. It should be noted that a new stretching vibration peak around $1700 \mathrm{~cm}^{-1}$ started to appear with the increase of air-blowing temperature (from ETP to ETP-300), which was attributed to carbonyl $\mathrm{C}=\mathrm{O}$. After air-blowing, the absorption peak intensity in $3300 \mathrm{~cm}^{-1}$ to $3600 \mathrm{~cm}^{-1}$ and $1650 \mathrm{~cm}^{-1}$ to $1750 \mathrm{~cm}^{-1}$ strengthened, suggesting that the content of oxygen functional groups, mainly hydroxyl $(-\mathrm{OH})$ and carboxyl $(-\mathrm{COOH})$, had a certain amount of increase. This was consistent with the results of elemental analysis. The increase of oxygen functional groups might indicate
Table 1 General properties of pitch precursors

\begin{tabular}{llllllll}
\hline Samples & SP $\left({ }^{\circ} \mathrm{C}\right)$ & Yield $(\%)$ & \multicolumn{6}{l}{ Elemental analysis (\%) } \\
\cline { 5 - 8 } & & & $\mathrm{C}$ & $\mathrm{H}$ & $\mathrm{N}$ & $\mathrm{S}$ & $\mathrm{O}$ \\
\hline ETP & 200 & 30.01 & 90.51 & 5.93 & 1.02 & 0.27 & 2.27 \\
ETP-200 & 196 & 33.34 & 88.71 & 5.59 & 1.01 & 0.24 & 4.45 \\
ETP-250 & 218 & 34.79 & 87.95 & 5.43 & 1.06 & 0.22 & 5.34 \\
ETP-300 & 225 & 36.88 & 87.41 & 5.32 & 1.03 & 0.23 & 6.01 \\
\hline
\end{tabular}



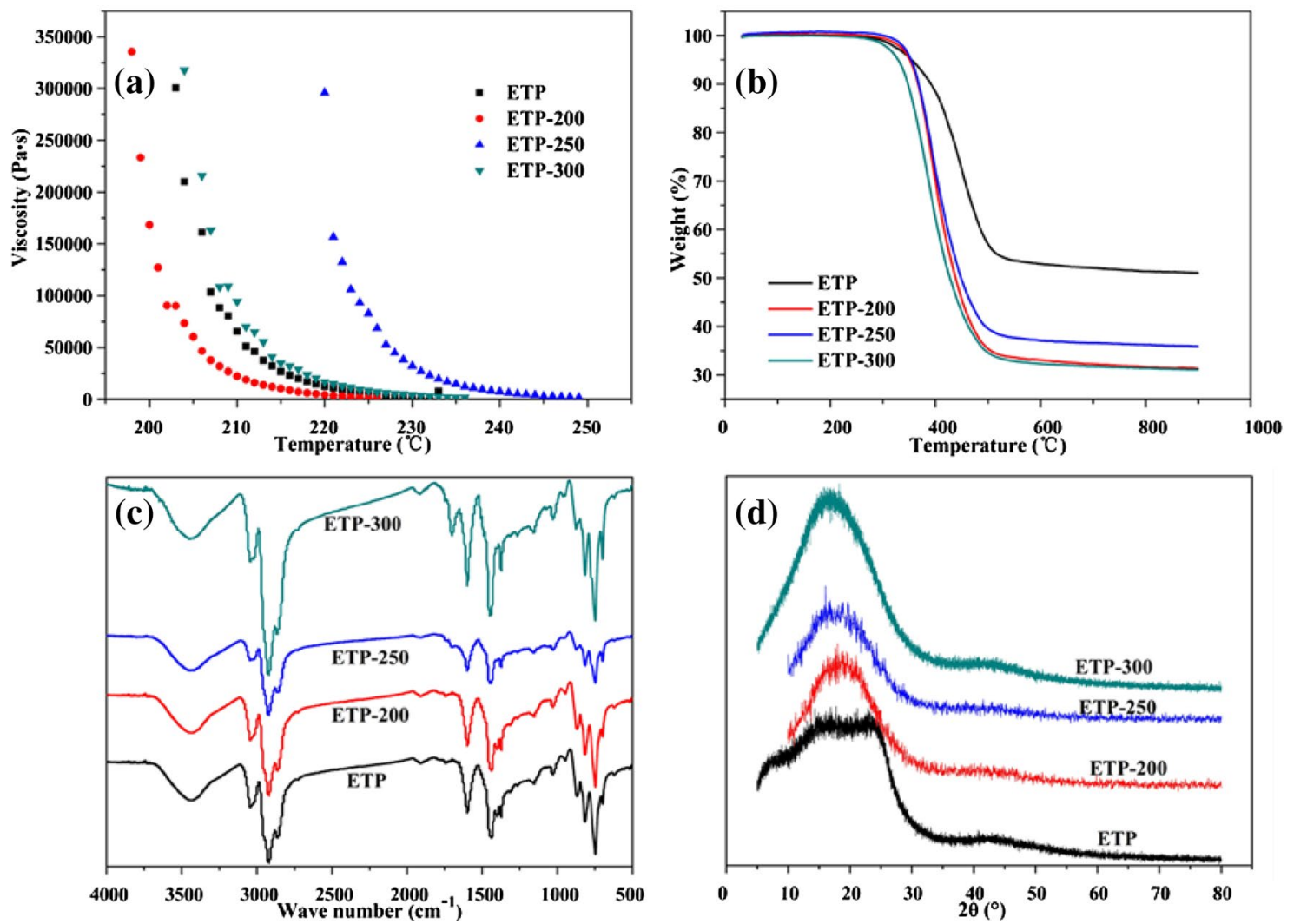

Fig. 1 The viscosity-temperature curves (a), TG curves (b), FT-IR spectra (c) and XRD spectra (d) of prepared pitch precursors

that oxygen served as bridged bond between of pitch molecules due to intermolecular cross-linking reaction during the air-blowing process.

In order to further investigate the structure and molecular order of oxidized pitches, XRD of four pitch precursors was performed and shown in Fig. $1 \mathrm{~d}$. All of them showed a broad peak between $10^{\circ}$ and $30^{\circ}$, which could be attributed to the amorphous carbon structure. As shown in Fig. 1d, ETP had another diffraction peak between $20^{\circ}$ and $30^{\circ}$. The peak was attributable to stacked graphite crystallite structure [26]. It proved that the presence of oxygen could hinder the order stack of molecules so that pitch without oxidation treatment had a more evidence stacked structure.

\subsection{Stabilization, carbonization, and activation of fibers}

Table 2 shows the yield and oxygen content of four pitch fibers during the stabilization, carbonization and activation processes. Compared with ETP-Fiber, oxidized pitchderived fiber had lower stabilization yield. Moreover, the stabilization yield and oxygen content of oxidized pitch-derived fiber slightly decreased with the increase of air-blowing temperature, which indicated that the introduced oxygen in pitch precursors reduced the degree of oxidative of pitch fibers, showing less oxygen uptake of fibers after stabilization. This conclusion could be inferred from the fact that more oxygen existed in the pitch precursors inhibited oxygen diffusing to the fiber during the stabilization process. It should be noted that stabilized
Table 2 Yield and oxygen content of fibers in the stabilization, carbonization and activation processes

\begin{tabular}{|c|c|c|c|c|c|c|}
\hline \multirow[t]{2}{*}{ Samples } & \multicolumn{2}{|c|}{ Stabilization } & \multicolumn{2}{|c|}{ Carbonization } & \multicolumn{2}{|c|}{ Activation } \\
\hline & Yield (\%) & $\mathrm{O}(\%)$ & Yield (\%) & $\mathrm{O}(\%)$ & Yield (\%) & $\mathrm{O}(\%)$ \\
\hline ETP-Fiber & 112.05 & 11.61 & 63.04 & 4.62 & 73.61 & 11.36 \\
\hline ETP-200-Fiber & 108.93 & 10.87 & 66.62 & 5.82 & 68.06 & 15.51 \\
\hline ETP-250-Fiber & 108.71 & 10.27 & 68.91 & 6.63 & 66.89 & 16.58 \\
\hline ETP-300-Fiber & 107.84 & 10.14 & 68.93 & 7.12 & 64.86 & 15.86 \\
\hline
\end{tabular}


fibers of oxidized pitches had higher carbonization yield than ETP-Fiber. Moreover, the oxygen content of CFs (it was $5.82 \%$ for ETP-200-CF, $6.03 \%$ for ETP-250-CF, 7.12\% for ETP-300-CF) were higher than that of ETP-CF (4.62\%) on the contrary, which suggested that less oxygen was released from the oxidized pitch-derived fibers during the carbonization process. The change of oxygen content indicated that the introduced oxygen in pitch precursors was more stable than the oxygen added during the stabilization process and oxidized pitch-derived stabilized fibers could remain more oxygen after carbonization at $800^{\circ} \mathrm{C}$. Thus, there would be more active sites in oxidized pitchderived CFs during the activation process. As a result, the activation yield decreased with the increase of the oxygen content of CFs, as ETP-200-CF was $68.06 \%$, ETP-250-CF was $66.89 \%$, and ETP-300-CF was $64.86 \%$, compared to $73.61 \%$ for ETP-CF, indicating that oxygen can promote the activation of CFs. Overall, the introduced oxygen in pitch precursors could impact the stabilization, carbonization and
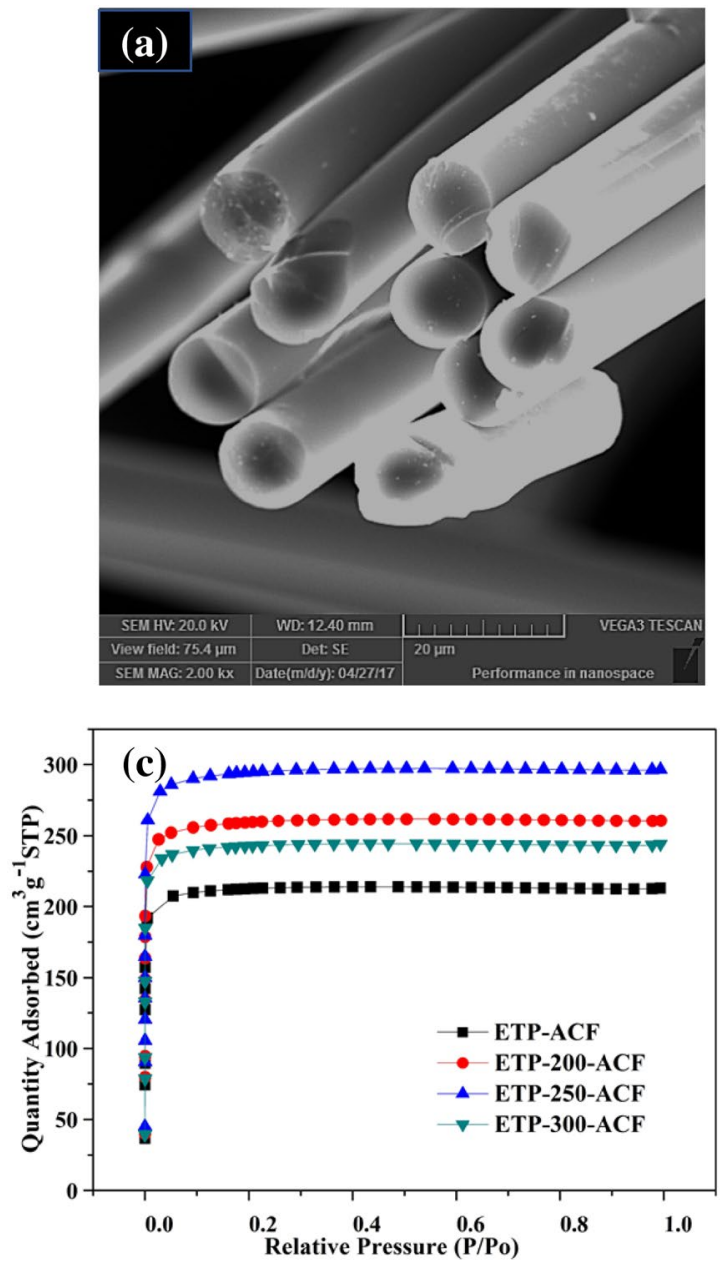

activation processes of the oxidized pitch-derived fibers, promising to prepare ACF with different porous texture and surface chemical properties.

SEM images of ETP-250-CF and ETP-250-ACF are shown in Fig. 2a, b. In Fig. 2a, ETP-250-CF had a smooth surface and no fusing phenomenon, which indicated that the stabilization conditions were appropriate. Comparing Fig. 2a, b, it could be seen that a special porous texture was formed during activation process due to the oxygen existed in CF. As shown in Fig. 2b, some hollow structure could be observed inside of ETP-250-ACF. The special hierarchical pore texture is expected to have a good application prospect in the field of catalytic adsorption of ACF.

\subsection{Porosity and surface chemistry characterization of activated carbon fibers}

Figure 2c presents the $\mathrm{N}_{2}$ adsorption isotherms obtained at $77 \mathrm{~K}$ for the prepared ACFs, and the pore textures of
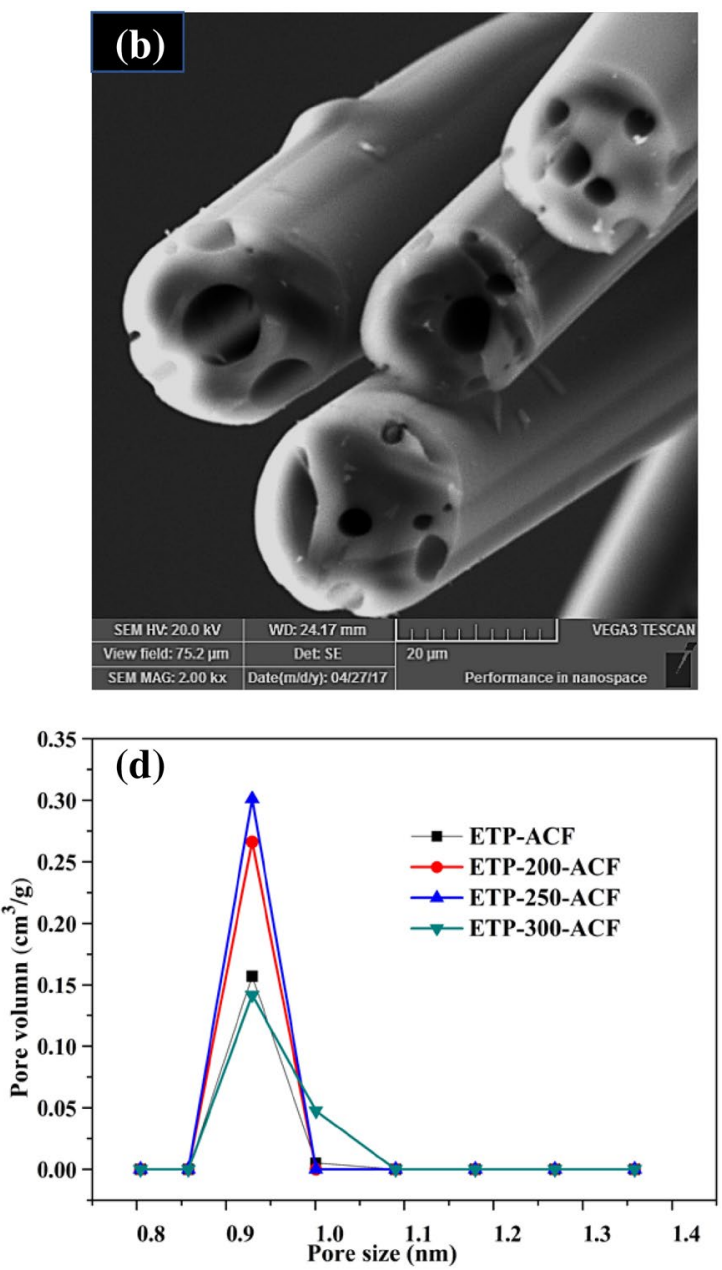

Fig. 2 SEM micrographs of ETP-250-CF (a) and ETP-250-ACF (b) and nitrogen adsorption and desorption isotherms at $77 \mathrm{~K}$ (c) and pore size distribution (d) of prepared pitch-based ACFs 
Table 3 Pore textures and oxygen functional groups of ACFs

\begin{tabular}{lclllll}
\hline Samples & $\mathrm{S}_{\mathrm{BET}}\left(\mathrm{m}^{2} / \mathrm{g}\right)$ & $\mathrm{V}_{\mathrm{t}}\left(\mathrm{cm}^{3} / \mathrm{g}\right)$ & $\mathrm{V}_{\text {mic }}\left(\mathrm{cm}^{3} / \mathrm{g}\right)$ & \multicolumn{3}{l}{$\begin{array}{l}\text { Oxygen functional groups } \\
(\mathrm{mmol} / \mathrm{g})\end{array}$} \\
\cline { 5 - 7 } & & & & $-\mathrm{COOH}$ & $\mathrm{C}-\mathrm{OOR}$ & $-\mathrm{OH}$ \\
\hline ETP-Fiber & 755 & 0.33 & 0.32 & 0.330 & 0.024 & 0.153 \\
ETP-200-Fiber & 922 & 0.40 & 0.38 & 0.403 & 0.049 & 0.168 \\
ETP-250-Fiber & 1047 & 0.46 & 0.43 & 0.536 & 0.043 & 0.193 \\
ETP-300-Fiber & 862 & 0.38 & 0.36 & 0.483 & 0.038 & 0.182 \\
\hline
\end{tabular}

obtained ACFs are listed in Table 3. All the isotherms are type I following the IUPAC classification [27], indicative of the microporous character of the prepared ACFs. Clearly, ACFs prepared from oxidized pitch precursors had a higher saturation adsorption capacity. Among them, ETP-250-ACF had the highest saturation adsorption as well as the highest $\mathrm{S}_{\mathrm{BET}}, \mathrm{V}_{\mathrm{t}}$ and $\mathrm{V}_{\text {mic, }}$ which was $1047 \mathrm{~m}^{2} / \mathrm{g}, 0.46 \mathrm{~cm}^{3} / \mathrm{g}$, and $0.43 \mathrm{~cm}^{3} / \mathrm{g}$, respectively. It was worth mentioning that ETP-300-ACF had lower adsorption capacity compared with ETP-200-ACF. Moreover, the $S_{B E T}, V_{t}$ and $V_{\text {mic }}$ of ETP300-ACF was all lower than that of ETP-200-CF, which might be due to the high oxygen content caused by excessive oxidative treatment. This assumption could be further confirmed in Fig. $2 \mathrm{~b}$ showing pore size distribution of the ACFs. The pore size distribution of all four ACFs was narrow, and almost all of them were concentrated in the micropore size range of $0.85-1.0 \mathrm{~nm}$. The pore size distribution of ETP-300-ACF was somewhat expanded with a small amount of pores size distributed in 1.0-1.1 nm, which indicated that the pore structure of ACFs prepared from the pitch precursor with high oxygen content was easy to enlarge.

The oxygen functional groups of ACFs from the Boehm titration results are listed in Table 3. As shown in Table 3, ACFs prepared from oxidized pitch precursors generally had more oxygen functional groups. Among them, ETP-250-ACF had $0.536 \mathrm{mmol} / \mathrm{g}$ carboxylic group, $0.043 \mathrm{mmol} / \mathrm{g}$ lactonic group and $0.193 \mathrm{mmol} / \mathrm{g}$ phenolic hydroxyl group on the surface compared with $0.330 \mathrm{mmol} / \mathrm{g}$ carboxylic group, $0.024 \mathrm{mmol} / \mathrm{g}$ lactonic group and $0.153 \mathrm{mmol} / \mathrm{g}$ phenolic hydroxyl group for ETPACF. It proved that the introduced oxygen in pitch precursors increased the oxygen functional groups of ACFs.

\section{Conclusion}

Three kinds of pitch precursors with different oxygen contents were prepared using ET as a raw material by air-blowing method. Compared with untreated pitch, oxidized pitch had higher oxygen content, and the introduced oxygen in pitch precursor was more stable than the oxygen added from stabilization process. Moreover, the oxygen existed in CFs prepared from oxidized pitch precursor could promoted the activation effect of CFs. Thus, ACF prepared from oxidized pitch precursor had more developed porous texture and richer oxygen functional groups and special pore structure. The introduction of oxygen into pitch precursor would be a good method to improve the porous structure and surface chemistry of ACF.

Acknowledgements The authors appreciate the support of Wuhan Luhua Yueda Chemical Co. Ltd, China for providing ethylene tar.

Author contributions JXY conceived and designed the experiments; HPW, JL and KS performed the experiments; HPW, JL and JXY analyzed the data; JXY and XKL reagents/materials/analysis tools; HPW and JXY wrote the paper.

Funding This research was funded by the National Science Foundation for Young Scientists of China [Grant Number 51702094] and the Natural Science Foundation for Young Scientists of Hunan Province, China [Grant Number 2017JJ3014].

\section{Compliance with ethical standards}

Conflict of interest The authors declare no conflict of interest.

\section{References}

1. Chiang YC, Juang RS (2017) Surface modifications of carbonaceous materials for carbon dioxide adsorption: a review. J Taiwan Inst Chem Eng 71:214-234

2. Lin SY, Zhang RJ, Jiang X, Yang TT, Lao JC, Zhu HW (2015) Gas adsorption properties of carbon materials and their applications in air purification. New Carbon Mater 30(6):502-510

3. Yu F, Li Y, Han S, Ma J (2016) Adsorptive removal of antibiotics from aqueous solution using carbon materials. Chemosphere 153:365-385

4. Kwiatkowski M (2009) Computer analysis of the microporous structure of activated carbon fibres using the fast multivariant identification procedure of adsorption system parameters. J Colloid Interface Sci 330(2):266-275

5. Liu JH, Yang R, Li SM (2006) Preparation and application of efficient $\mathrm{TiO}_{2} / \mathrm{ACF}$ s photocatalyst. J Environ Sci 18(5):979-982

6. Zhang X, Gao B, Creamer AE, Cao C, Li Y (2017) Adsorption of VOCs onto engineered carbon materials: a review. J Hazard Mater 338:102-123

7. Lee YS, Kim YH, Hong JS, Suh JK, Cho GJ (2007) The adsorption properties of surface modified activated carbon fibers for hydrogen storages. Catal Today 120(3-4):420-425 
8. Park SJ, Kim BJ (2004) Influence of oxygen plasma treatment on hydrogen chloride removal of activated carbon fibers. J Colloid Interface Sci 275(2):590-595

9. Yang J, Juan P, Shen Z, Guo R, Jia J, Fang H, Wang Y (2006) Removal of carbon disulfide $\left(\mathrm{CS}_{2}\right)$ from water via adsorption on active carbon fiber (ACF). Carbon 44(8):1367-1375

10. Maciá-Agulló JA, Moore BC, Cazorla-Amorós D, Linares-Solano A (2004) Activation of coal tar pitch carbon fibres: physical activation vs. chemical activation. Carbon 42(7):1367-1370

11. Díez $N$, Álvarez $P$, Granda $M$, Blanco $C$, Santamaría R, Menéndez $R$ (2015) A novel approach for the production of chemically activated carbon fibers. Chem Eng J 260:463-468

12. Alcañiz-Monge J, Lillo-Ródenas MÁ, Bueno-López A, IllánGómez MJ (2007) The influence of iron chloride addition to the precursor pitch on the formation of activated carbon fibers. Microporous Mesoporous Mater 100(1-3):202-209

13. Carrott PJM, Nabais JMV, Ribeiro Carrott MML, Menéndez JA (2004) Microwave heating as a novel method for introducing molecular sieve properties into activated carbon fibres. Carbon 42(1):227-229

14. Lozano-Castelló D, Maciá-Agulló JA, Cazorla-Amorós D, LinaresSolano A, Müller M, Burghammer M, Riekel C (2006) Isotropic and anisotropic microporosity development upon chemical activation of carbon fibers, revealed by microbeam small-angle X-ray scattering. Carbon 44(7):1121-1129

15. Derbyshire F, Andrews $R$, Jacques $D$, Jagtoyen $M$, Kimber $G$, Rantell T (2001) Synthesis of isotropic carbon fibers and activated carbon fibers from pitch precursors. Fuel 80(3):345-356

16. Vilaplana-Ortego E, Maciá-Agulló JA, Alcañiz-Monge J, CazorlaAmorós D, Linares-Solano A (2008) Comparative study of the micropore development on physical activation of carbon fibers from coal tar and petroleum pitches. Microporous Mesoporous Mater 112(1-3):125-132

17. Tekinalp HL, Cervo EG, Fathollahi B, Thies MC (2013) The effect of molecular composition and structure on the development of porosity in pitch-based activated carbon fibers. Carbon 52:267-277

18. Mendez A, Bermejo J, Blanco C, Santamaria R, Suelves I, Menen$\operatorname{dez} \mathrm{R}$ (2001) Structural characterization of high-softening-point pitches by oxidation with $\mathrm{RuO}_{4}$. Energy Fuels 15(1):128-134

19. Mendez A, Bermejo J, Santamaria R, Blanco CG, Menendez R (2000) Selective oxidation of PAH with $\mathrm{RuO}_{4}$ as a preliminary step in the characterization of polymerized pitches. Energy Fuels 14(4):936-942

20. Ge CZ, Sun ZL, Yang HX, Long DH, Qiao WM, Ling LC (2018) Preparation and characterization of high softening point and homogeneous isotropic pitches produced from distilled ethylene tar by a novel bromination method. New Carbon Mater 33(1):71-81

21. Dominguez A, Blanco C, Santamaria R, Granda M, Blanco CG, Menendez R (2004) Monitoring coal-tar pitch composition changes during air-blowing by gas chromatography. J Chromatogr A 1026(1-2):231-238

22. Menendez R, Blanco C, Santamaria R, Dominguez A, Blanco CG, Suelves I, Herod AA, Morgan TG, Kandiyoti R (2002) Effects of air-blowing on the molecular size and structure of coal-tar pitch components. Energy Fuels 16(6):1540-1549

23. Salame II, Bandosz TJ (2001) Surface chemistry of activated carbons: combining the results of temperature-programmed desorption, boehm, and potentiometric titrations. J Colloid Interface Sci 240(1):252-258

24. Liu D, Lou B, Chang G, Zhang Y, Yu R, Li Z, Wu C, Li M, Chen Q (2018) Study on effect of cross-linked structures induced by oxidative treatment of aromatic hydrocarbon oil on subsequent carbonized behaviors. Fuel 231:495-506

25. Qiu W, Dou K, Zhou Y, Huang H, Chen Y, Lu H (2018) Hierarchical pore structure of activated carbon fabricated by $\mathrm{CO}_{2} /$ microwave for volatile organic compounds adsorption. Chin J Chem Eng 26(1):81-88

26. Liu W, Zhang Q, Zhao G (2015) Influence of activation time on the microstructure and antibacterial activity of nanosilver-containing activated carbon fibers prepared from liquefied wood. Fibers Polym 16(3):522-528

27. Baur GB, Beswick O, Spring J, Yuranov I, Kiwi-Minsker L (2015) Activated carbon fibers for efficient VOC removal from diluted streams: the role of surface functionalities. Adsorpt J Int Adsorpt Soc 21(4):255-264

Publisher's Note Springer Nature remains neutral with regard to jurisdictional claims in published maps and institutional affiliations. 